\title{
Co-application of soil superabsorbent polymer and foliar fulvic acid to increase tolerance to water deficit maize: photosynthesis, water parameters, and proline
}

\author{
Wei Yang ${ }^{1}$, Pinfang $\mathrm{Li}^{1,2^{*}}$, Shiwen Guo ${ }^{1}$, Riquan Song ${ }^{3}$, and Jian $\mathrm{Yu}^{3}$ \\ ${ }^{1}$ China Agricultural University, College of Resources and Environmental Sciences, Beijing 100193, China. \\ ${ }^{2}$ Key Laboratory of Arable Land Conservation (North China), Ministry of Agriculture, Beijing 100193, China. \\ *Corresponding author (pfli@cau.edu.cn). \\ ${ }^{3}$ Water Resources Research Institute of Inner Mongolia, Hohhot 010052, China.
}

Received: 3 October 2018; Accepted: 11 March 2019; doi:10.4067/S0718-58392019000300435

\begin{abstract}
Fulvic acid (FA) and superabsorbent polymer (SAP) are widely applied to improve crop growth and yield under water deficit conditions, but little is known about the changes in crop physiological parameters related to water deficit tolerance when SAP and FA are combined. A pot test with maize (Zea mays L.) plants was conducted to examine the combined effect on photosynthesis, leaf water, proline, and growth under soil water deficit. Maize plants were subjected to two soil moisture conditions at the late crop growth phase: water deficit (WD, 50\% field capacity) and well-watered (WW, 80\% field capacity). The SAP $\left(4.5 \mathrm{~g} \mathrm{~m}^{-2}\right)$ was mixed into the soil layer at sowing and the FA solution $\left(2 \mathrm{~g} \mathrm{~L}^{-1}\right)$ was sprayed twice during water control. The combined application significantly improved maize grain yield under both watering conditions. The net photosynthesis rate, intrinsic quantum yield, fluorescent parameter $\left(\mathrm{F}_{\mathrm{v}} / \mathrm{F}_{\mathrm{m}}\right)$, and chlorophyll content all improved with the combined application under both watering regimes. The compensating effect of combining chemicals on yield and photosynthesis parameters was higher than when applied alone under the two watering conditions. For prolonged and WD conditions, leaf proline and water content were higher under the combined treatment than when used separately. Under the WD conditions treated with FA and SAP, $\mathrm{F}_{\mathrm{v}} / \mathrm{F}_{\mathrm{m}}$ had positive significant correlations with leaf water content and osmotic potential; leaf proline did not show any correlations with either the osmotic potential or leaf water content. This result demonstrated that SAP and FA could be combined to maintain high leaf proline and improve photosynthesis to mitigate adverse effects of moderate water storage on maize growth.
\end{abstract}

Key words: Humic substances, maize, proline, photosynthetic rate, superabsorbent hydrogel.

\section{INTRODUCTION}

Water deficit is the main environmental factor affecting crop production worldwide; therefore, it is important to mitigate such a deficit to enhance crop yield (Cattivelli et al., 2008; Anjum et al., 2011). Maize (Zea mays L.) is cultivated in a wide range of climates and soils in China. It is currently grown as a dominant crop in central Inner Mongolia in northern China and has a drought index $>3$. Precipitation is unpredictable in this region, which receives 250 to $400 \mathrm{~mm}$ annual rainfall; approximately $60 \%$ of annual precipitation is lost through evaporation, leaving only $25 \%$ to $33 \%$ for crop growth (Yang et al., 2017). Crop growth thus heavily depends on irrigation from limited water resources. Additionally, the soil in this area has poor water-holding capacity because of low clay content and limited organic matter content; irrigation water therefore rapidly percolates below the root zone (Li, 2003; Yu et al., 2017). 
The superabsorbent polymer (SAP) has a three-dimensional network structure containing hydrophilic functional groups and ionized ions on its surface (Moini and Kabiri, 2015). It can retain as much as 100 to 1000 times its own weight in water by an osmotic potential gradient between the inside and outside of the membrane. The SAP increases waterretention ability under dry conditions in low clay content soils more than in high clay content soils (Yu et al., 2017). The application of superabsorbent hydrogel to soil promotes irrigation water-use efficiency because of its repeated absorption of soil water and slow release to the crops (Koupai et al., 2008; Liao et al., 2018a), and it reduces crop damage caused by soil water shortage (Khadem et al., 2010; Yang et al., 2014; Cao et al., 2017). Fulvic acid (FA) is a multifunctional growthregulating compound similar to antitranspirants and auxins (Anjum et al., 2011; Zhang et al., 2016; Yang et al., 2017). It has been widely applied to field crops, horticultural plants, and trees in China for over $20 \mathrm{yr}$ (Aggag et al., 2015; Lotfi et al., 2015). Spraying with FA has the potential to reduce water losses by decreasing leaf stomatal transpiration (Li et al., 2005; Calvo et al., 2014), improve plant drought tolerance, and increase crop water-use efficiency (Faralli et al., 2017; Yang et al., 2017). The FA application in wheat increased water uptake by improving root hydraulic conductance and cell membrane permeability (Delfine et al., 2005), and plant adaptability to soil water deficit was enhanced.

Photosynthesis-related parameters such as net photosynthetic rate, chlorophyll content, and fluorescence parameter $\left(\mathrm{F}_{\mathrm{v}} / \mathrm{F}_{\mathrm{m}}\right)$ are the basis for crop growth and yield; these metrics are used to screen the recovery of plants subjected to soil water shortage (Lotfi et al., 2015). In addition, plants growing under soil water deficit conditions produce proline to overcome cell dehydration (Ashraf et al., 2011). Under moderate soil water deficit conditions, soil SAP application indirectly promotes photosynthesis (Hartwigsen and Evans, 2000), increases chlorophyll levels (Najafinezhad et al., 2015), and also improves leaf water status (Islam et al., 2011). In maize, FA spraying increased leaf proline, net photosynthetic rate, and chlorophyll levels under drought conditions (Anjum et al., 2011). Foliar application of FA to tomato plants increased osmotic potential and leaf tissue water content under soil water shortage conditions (Aggag et al., 2015). Leaf proline and photochemical quantum efficiency were greatly improved by spraying FA on the wheat canopy (Lotfi et al., 2015; Maibodi et al., 2015).

Few recent studies have demonstrated that combining FA and SAP has favorable effects in plants by improving crop production under low rainfall conditions. Yang et al. (2017) tested the combined use of SAP and FA and concluded that it improved maize plant water-use efficiency under moderate drought conditions. Liao et al. (2018b) showed that combining FA and SAP reduced water loss and increased root water uptake in a rainfed soil-maize system, mainly by combining the regulation of exogenous hormones and root length. However, the study of the combined effect of the FA and SAP treatment on plant physiological parameters related to water deficit tolerance was negligible. The objective of this study was to determine the response of plant photosynthesis and leaf water relationships to FA and SAP treatments under moderate soil water deficiency.

\section{MATERIALS AND METHODS}

\section{Study site and crop growth conditions}

A field-based maize plant pot test was conducted at the Helin Experimental Station for Water-Saving and Irrigation, Inner Mongolia $\left(40^{\circ} 16^{\prime} \mathrm{N}, 111^{\circ} 46^{\prime} \mathrm{E}\right.$; $1130 \mathrm{~m}$ a.s.l.), P.R. China in 2015 . The highest, lowest, and mean annual temperatures at the site were $37.5,-34.5$, and $5.6^{\circ} \mathrm{C}$, respectively. Annual pan evaporation and rainfall were $1850 \mathrm{~mm}$ and $395 \mathrm{~mm}$, respectively. Total rainfall was $365 \mathrm{~mm}$ and mean temperature was $20.0^{\circ} \mathrm{C}$ during the plant growth period from 22 May to 10 October; these were based on records from a weather station near the experimental field.

The pots ( $28 \mathrm{~cm}$ height, $33 \mathrm{~cm}$ inner diameter) were sealed with permeable plastic film at the bottom and filled with $18.7 \mathrm{~kg}$ air-dried soil. Before sowing, $4 \mathrm{~L}$ local groundwater was used to irrigate each pot. Pots were then buried in the soil so that the tops were level with the field. Prior to filling the pots, each batch of soil was evenly mixed with $11.0 \mathrm{~g}$ compound fertilizer $\left(\mathrm{N}: \mathrm{P}_{2} \mathrm{O}_{5}: \mathrm{K}_{2} \mathrm{O}=26: 14: 6\right)$. Pots were divided into the two groups of without SAP (superabsorbent polymer) and with SAP. For the SAP group, $0.9 \mathrm{~g} \mathrm{SAP}$ was added to the upper $5 \mathrm{~cm}$ soil layer (equivalent to $4.5 \mathrm{~g} \mathrm{~m}^{-2}$ ). Three maize seeds ('Jidan No. 502') were sown in each pot at a $5 \mathrm{~cm}$ depth. When the plants had germinated and grown to the three-leaf stage, two plants were removed. At the bell stage, $6.9 \mathrm{~g}$ common urea and $12.3 \mathrm{~g}$ potassium sulfate were applied to the pots. A shelter with plastic material was used to protect the pots from the rain. 


\section{Materials}

The SAP used in the study (Chang'an Group Co. Ltd., Dongying, China) was a particulate organic material with a 0.4 to $1.5 \mathrm{~mm}$ particle diameter and $200 \mathrm{~g} \mathrm{~g}^{-1}$ maximum deionized water absorption ratio. It was composed of $70 \%$ negatively charged acrylic-acrylamide polymers with $20 \%$ hydrolysis synthesized with $30 \%$ attapulgite. Fulvic acid (FA) has the same behavior toward antitranspirants and auxins (Anjum et al., 2011; Zhang et al., 2016; Yang et al., 2017; Liao et al., 2018a); supplies were obtained from the Huitong Handilong Humic Acid Co., Ltd., Xinjiang, China. Soil was collected from the top 20-cm depth in the experimental field. Soil texture is classified as sandy loam. The organic matter was $2.54 \mathrm{~g} \mathrm{~kg}^{-1}$, and available $\mathrm{N}, \mathrm{P}$, and $\mathrm{K}$ were, $84.3,5.1$, and $34.5 \mathrm{mg} \mathrm{kg}^{-1}$, respectively.

\section{Experimental design}

There were eight treatment combinations in the present study. The factorial treatments were conducted by combining two water supply groups, well-watered (WW) and water deficit (WD), two soil amendments, without SAP or with SAP application, and two foliar treatments, without FA or with FA spraying, with six replicates for each treatment. The experiment was performed with a completely randomized design, and the WW group without the combined FA and SAP treatment was considered as the control (CK).

Prior to the water treatment, all plots were regularly irrigated until heading. Plants for the without SAP and with SAP groups were grown under WD (50\% field capacity) or WW (80\% field capacity) conditions from the heading stage (8August) to the grain fill stage (4 September). After this water treatment, all plants were well-irrigated until harvest. The amount of water provided was based on the difference in pot weight; pots were weighed every 2 or $3 \mathrm{~d}$ at 18:00 h. For each treatment, local groundwater was supplied to the pots as needed to maintain the desired moisture levels during the water treatment period. After the water treatment, all plants were normally watered until harvest. The change in daily evapotranspiration during the water treatment period for each treatment is shown in Figure 1. The FA was dissolved in distilled water to the appropriate concentration $\left(2 \mathrm{~g} \mathrm{~L}^{-1}\right)$ according to author recommendations (Celik et al., 2010; Suh et al., 2016; Zhang et al., 2016). The FA solution was sprayed on plant leaves (100 mL per plant) with a hand-held power sprayer 2 and $9 \mathrm{~d}$ after implementing the water treatment. Plants without the FA application were sprayed with an equal amount of distilled water.

\section{Light response curve}

On the second day following the end of each experimental period (5 September), three leaves were selected from plants in each treatment to perform a light response curve. The net photosynthetic rate $\left(\mathrm{P}_{\mathrm{n}}\right)$ was measured at 2000, 1800, 1500, $1200,1000,800,600,400,200,100,50,20$, and $0 \mu \mathrm{mol}$ (quantum) $\mathrm{m}^{-2} \mathrm{~s}^{-1}$ photosynthetic photon flux density (I) with a

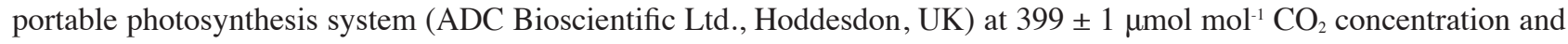

Figure 1. Change in evapotranspiration (ET) for maize plants after fulvic acid (FA) and superabsorbent polymer (SAP) application under well-watered (WW) and water deficit (WD) conditions from early tassel to grain fill.

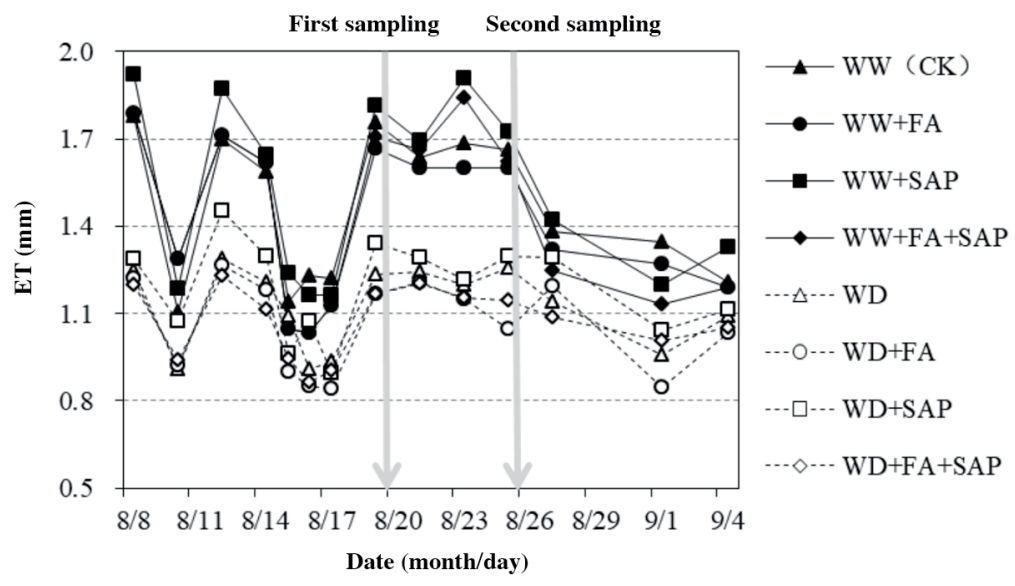


$25^{\circ} \mathrm{C}$ leaf chamber temperature. The $\mathrm{P}_{\mathrm{n}}$ to I response curve was performed using the model described by Ye et al. (2013) expressed by the following equation

$$
P_{n}(I)=\alpha \frac{1-\beta \times I}{1+\gamma \times I}\left(I-I_{c p}\right)
$$

where $P_{n}$ is the net photosynthetic rate, $I$ is the photosynthetic photon flux density, parameters $\alpha, \beta$, and $\gamma$ are the coefficients that are not correlated with $I$, and $I_{c p}$ is the light compensation point. Maximum net photosynthetic rate $\left(\mathrm{P}_{\mathrm{n} \text { (max) }}\right)$, light saturation point $\left(\mathrm{I}_{\mathrm{sp}}\right)$, dark respiration rate $\left(\mathrm{R}_{\mathrm{d}}\right)$, and intrinsic quantum yield $\left(\mathrm{Q}_{\mathrm{y}}\right)$ were estimated by fitting the curve. Fitting the $P_{n}$ to I curve was performed by Microsoft Excel 2010 (Lobo et al., 2013; http://photosynthetic.sinaapp.com/calc.html).

\section{Chlorophyll fluorescence}

Figure 1 shows that at $12 \mathrm{~d}$ (first sampling) and $18 \mathrm{~d}$ (second sampling) after implementing the water treatment, plants from each treatment were selected to measure the chlorophyll content and fluorescence parameters. Total chlorophyll content $(\mathrm{Chl} \mathrm{a}+\mathrm{b})$ from the upper, middle, and bottom of the leaves of three plants was measured with a CCM-300 detector system (Opti-Sciences Inc., Hudson, New Hampshire, USA). Chlorophyll fluorescence was also determined with a pulse modulated fluorometer OS-5p (Opti-Sciences), and the ratio of variable fluorescence $\left(\mathrm{F}_{\mathrm{v}}\right)$ to maximum fluorescence $\left(\mathrm{F}_{\mathrm{m}}\right)$ was determined with a leaf that had been dark-adapted for $20 \mathrm{~min}$. A red LED (light-emitting diode) was used as the light source. Modulation intensity and detector gain were maintained at 16 and 5, respectively.

\section{Leaf water parameters and proline}

The samples used to determine leaf relative water content (RWC) were wrapped in aluminum paper and then transferred to liquid nitrogen for storage until measurement. They were subsequently used to measure leaf osmotic potential $\left(\Psi_{\pi}\right)$ according to the protocol described by del Amor et al. (2010). Leaf RWC was estimated with fresh samples, approximately $1.00 \mathrm{~g}$ fresh leaf sample (W1) was placed in distilled water to obtain the saturation weight (W2) and dried at $75^{\circ} \mathrm{C}$ for $24 \mathrm{~h}$ to obtain dry mass (W3). The RWC was calculated as RWC (\%) $=[(\mathrm{W} 1-\mathrm{W} 3) /(\mathrm{W} 2-\mathrm{W} 3)] \times 100$. On the sampling day, approximately $0.50 \mathrm{~g}$ leaf tissue was used for soluble proline extraction and measurement based on procedures specified by Bates et al. (1973).

\section{Yield components}

At plant physiological maturity, plants from each individual treatment combination were collected and analyzed to calculate aboveground dry biomass, yield, and yield components. Aboveground tissues were oven-dried at $75^{\circ} \mathrm{C}$ for $72 \mathrm{~h}$. Grain water content was measured by oven drying $100 \mathrm{~g}$ kernel at $105^{\circ} \mathrm{C}$ for $24 \mathrm{~h}$.

\section{Statistical analysis}

All data for each sampling for the eight treatments were subjected to ANOVA using a three-factor completely randomized design. Differences in each parameter for each sampling were compared by Duncan's test at $\alpha=0.05$ with the SPSS software package (version 19.0; IBM, Armonk, New York, USA).

\section{RESULTS}

\section{Light response properties}

The regression equation provided a good simulation of the relationship between $\mathrm{P}_{\mathrm{n}}$ and I under two watering regimes treated with FA and SAP $\left(\mathrm{R}^{2}=0.98-0.98\right.$; Figure 2$)$. Therefore, the equation could be used to estimate the photosynthesisrelated parameters by fitting the curve. Based on the ANOVA, soil moisture, soil SAP, and foliar FA had significant main effects on $P_{n(\max )}, I_{s p}, R_{d}$, and $Q_{y}$. Interactive effects of FA and SAP on photosynthetic parameters under WW or WD conditions were nonsignificant. Under both watering regimes, $P_{n(\max )}, R_{d}$, and $Q_{y}$ showed a generally increasing trend; $I_{s p}$ showed a decreasing trend while maintaining optimal $\mathrm{I}_{\mathrm{cp}}$ (Table 1). When comparing CK under WD conditions, $\mathrm{P}_{\mathrm{n}(\max )}$ decreased by $28.1 \%$ and $33.9 \%$ in plots treated with FA or SAP, respectively, and decreased by $16.4 \%$ in plots treated with both chemicals. When comparing control plots under WW conditions, $\mathrm{P}_{n(\max )}$ was unchanged when FA or soil SAP were 
Figure 2. Net photosynthetic rate $\left(P_{n}\right)$ response to photosynthetic photon flux density $(I)$ in maize plants treated with fulvic acid (FA) and superabsorbent polymer (SAP) under well-watered (WW) (a), and waterdeficit (WD) conditions (b). Both dashed and solid lines indicate $P_{n}$ levels simulated at $I<2000 \mu \mathrm{mol}$ (quantum) $\mathrm{m}^{-2} \mathrm{~s}^{-1}$. Colored symbols indicate $P_{\mathrm{n}}$ levels measured at I equal to $2000,1800,1500,1200,1000,800,600,400,200,100,50,20$, and $0 \mu \mathrm{mol}(q u a n t u m) \cdot \mathrm{m}^{-2} \mathrm{~s}^{-1}$.
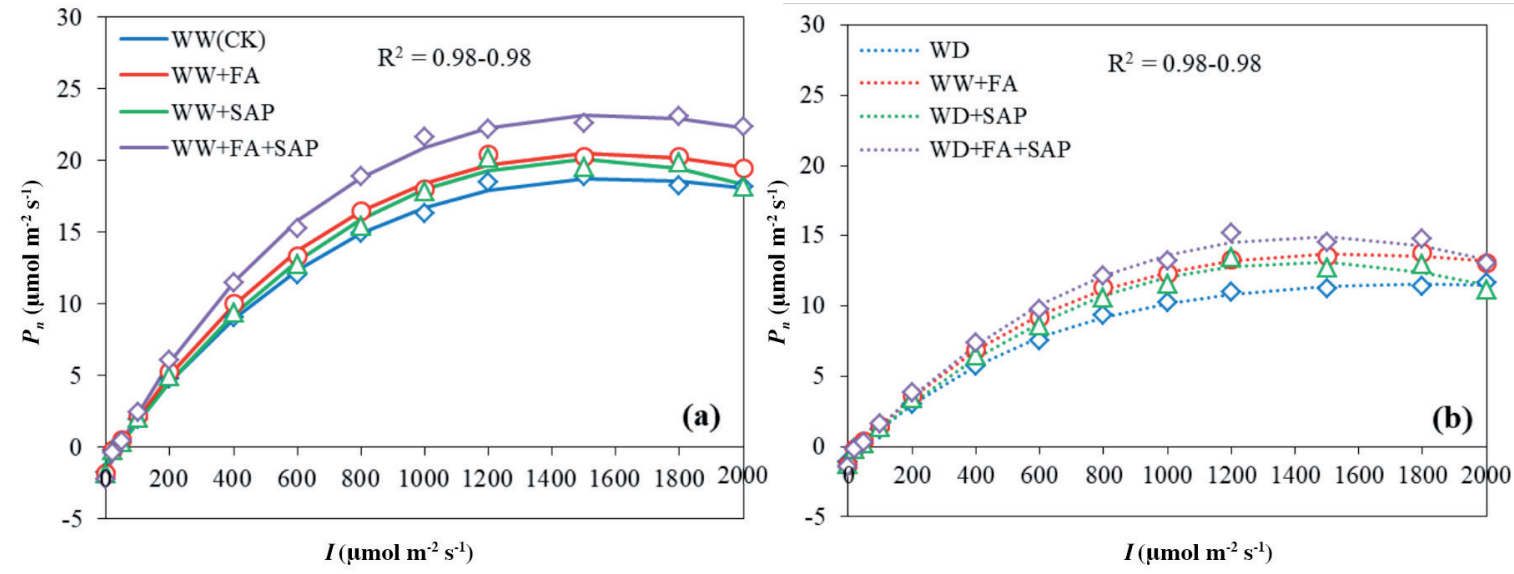

Table 1. Maximum net photosynthetic rate $\left(P_{n(\max )}\right)$, light saturation point $\left(I_{\mathrm{sp}}\right)$, light compensation point $\left(I_{\mathrm{cp}}\right)$, dark respiration rate $\left(R_{d}\right)$, and intrinsic quantum yield $\left(Q_{y}\right)$ in maize plants treated with fulvic acid (FA) and superabsorbent polymer (SAP) under well-watered (WW) and water deficit (WD) conditions. Measurements were taken $2 \mathrm{~d}$ after the water treatment ended.

\begin{tabular}{|c|c|c|c|c|c|}
\hline Treatment & $P_{n(\max )}$ & $I_{\mathrm{sp}}$ & $I_{\mathrm{cp}}$ & $\mathrm{R}_{\mathrm{d}}$ & $\mathrm{Q}_{\mathrm{y}}$ \\
\hline & \multicolumn{4}{|c|}{$\longrightarrow \mu \mathrm{mol}\left(\mathrm{CO}_{2}\right) \mathrm{m}^{-2} \mathrm{~s}^{-1} \longrightarrow$} & $\mu \mathrm{mol}$ (quantum) $\mathrm{m}^{-2} \mathrm{~s}^{-1}$ \\
\hline WW (CK) & $18.7 \mathrm{bc}$ & $1601 b$ & $36.9 \mathrm{a}$ & $1.22 \mathrm{~b}$ & $0.049 \mathrm{bc}$ \\
\hline WW+FA & $20.5 b$ & $1560 \mathrm{bc}$ & $38.4 \mathrm{a}$ & $1.29 \mathrm{~b}$ & $0.056 \mathrm{~b}$ \\
\hline WW+SAP & $20.0 \mathrm{~b}$ & $1508 \mathrm{c}$ & $37.7 \mathrm{a}$ & $1.17 \mathrm{~b}$ & $0.053 \mathrm{~b}$ \\
\hline $\mathrm{WW}+\mathrm{FA}+\mathrm{SAP}$ & $23.2 \mathrm{a}$ & $1581 b c$ & $39.9 \mathrm{a}$ & $1.70 \mathrm{a}$ & $0.065 \mathrm{a}$ \\
\hline WD & $11.6 \mathrm{~d}$ & $1769 \mathrm{a}$ & $36.1 \mathrm{a}$ & $0.78 \mathrm{~d}$ & $0.031 \mathrm{e}$ \\
\hline WD+FA & $13.7 \mathrm{~cd}$ & $1574 \mathrm{bc}$ & $37.7 \mathrm{a}$ & $0.96 \mathrm{c}$ & $0.039 \mathrm{~d}$ \\
\hline WD+SAP & $13.2 \mathrm{~cd}$ & $1433 d$ & $38.9 \mathrm{a}$ & $0.85 \mathrm{~cd}$ & $0.038 \mathrm{~d}$ \\
\hline $\mathrm{WD}+\mathrm{FA}+\mathrm{SAP}$ & $15.0 \mathrm{c}$ & $1450 \mathrm{~d}$ & $38.1 \mathrm{a}$ & $0.92 \mathrm{c}$ & $0.044 \mathrm{c}$ \\
\hline ANOVA (main effects) & & & & & \\
\hline Moisture & $* *$ & $* *$ & ns & $* *$ & $* *$ \\
\hline FA & & & & & \\
\hline SAP & $* *$ & ns & $\mathrm{ns}$ & * & $* *$ \\
\hline Moisture×FA & $\mathrm{ns}$ & ns & ns & ns & ns \\
\hline Moisture×SAP & $\mathrm{ns}$ & ns & ns & ns & ns \\
\hline $\mathrm{FA} \times \mathrm{SAP}$ & ns & * & ns & ns & ns \\
\hline Moisture $\times F A \times S A P$ & ns & ns & ns & ns & ns \\
\hline
\end{tabular}

Values followed by different letters within each column are significantly different according to Duncan's test at $\alpha=0.05$.

", "*Significant at $\alpha=0.05$ and $\alpha=0.01$, respectively; ns: nonsignificant differences.

provided as a foliar treatment. The $\mathrm{Q}_{\mathrm{y}}$ values improved by $26.7 \%$ and $25.4 \%$ in plots treated with FA or SAP, respectively. In contrast, the combined use of both chemicals significantly improved $\mathrm{P}_{\mathrm{n}(\max )}$ by $29.3 \%$ and $\mathrm{Q}_{\mathrm{y}}$ by $46.7 \%$ when compared with the control plots under WD conditions. The combined effect on photosynthesis of these two chemicals was also greater compared with the effects when applied alone. Using both FA and SAP significantly improved $\mathrm{R}_{\mathrm{d}}$ by $39.3 \%$ under WW conditions and 20\% under WD conditions. Under the WD conditions, $\mathrm{I}_{\mathrm{sp}}$ values decreased by $18 \%$ and $9 \%$ in the combined FA and SAP treatments, respectively, compared with the control plots and FA spraying alone. However, $\mathrm{I}_{\mathrm{sp}}$ in the FA, SAP, and combined treatments were nonsignificant under WW conditions. 


\section{Chlorophyll fluorescence}

In the absence of either exogenous chemical, 12 or $18 \mathrm{~d}$ after the WD treatment, $\mathrm{Chl}(\mathrm{a}+\mathrm{b})$ and $\mathrm{F}_{\mathrm{v}} / \mathrm{F}_{\mathrm{m}}$ values were lower in the WD group than in the WW group (Figures 3 and 4). Fulvic acid and SAP alone had no effect on Chl (a+b) and $\mathrm{F}_{v} / \mathrm{F}_{\mathrm{m}}$ after $12 \mathrm{~d}$ of WD treatment. However, under WD conditions, both combined chemicals, as compared with control plants, significantly improved $\mathrm{Chl}(\mathrm{a}+\mathrm{b})$ by $17.4 \%$ and $\mathrm{F}_{\mathrm{v}} / \mathrm{F}_{\mathrm{m}}$ by $10.6 \%$. In contrast, at $12 \mathrm{~d}$ after implementing WW conditions, $\mathrm{Chl}(\mathrm{a}+\mathrm{b})$ and $\mathrm{F}_{\mathrm{v}} / \mathrm{F}_{\mathrm{m}}$ values were nonsignificantly different in FA and SAP taken individually, whereas they significantly increased by $22.3 \%$ and $14.1 \%$ in the combined treatment, respectively. When moisture regimes were established until day 18 , the combination of both chemicals significantly improved the $\mathrm{Chl}(\mathrm{a}+\mathrm{b})$ content by $12 \%$ and $16 \%$ under WD and WW conditions, respectively.

\section{Leaf water and proline}

Based on the ANOVA (Table 2), soil moisture and SAP showed significant main effects $(\mathrm{P}<0.05)$ and interactions between these parameters. Soil moisture and FA had significant main effects on $\Psi_{\pi}$ and RWC (except for $12 \mathrm{~d}$ after starting CK); soil moisture and SAP with FA revealed interactions on $\Psi_{\pi}$. When these two chemicals were not added, and compared with the WW group (CK), $\Psi_{\pi}$ and RWC significantly decreased by $21.4 \%$ and $11.7 \%$, respectively, at $12 \mathrm{~d}$ after being subjected to the WD treatment, and by $26.7 \%$ and $14.2 \%$, respectively, at $18 \mathrm{~d}$ after being subjected to the WD treatment. Fulvic acid and SAP alone or combined had no effect on $\Psi_{\pi}$ and RWC after 12 and $18 \mathrm{~d}$ of WW. When WD was established until day

Figure 3. Total chlorophyll $(\mathrm{Chl}(\mathrm{a}+\mathrm{b}))$ in maize plants treated with fulvic acid (FA) and superabsorbent polymer (SAP) under well-watered (WW) and water deficit (WD) conditions for 12 (a) or $18 \mathrm{~d}$ (b), respectively.
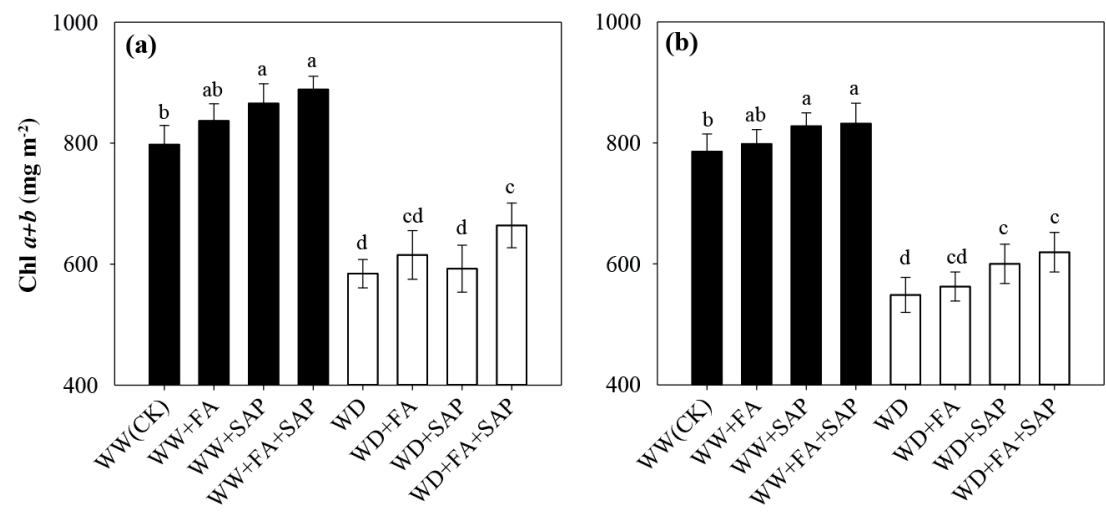

Different letters above columns indicate significant differences at $\alpha=0.05$.

Figure 4. Fluorescence parameter $\left(F_{v} / F_{m}\right)$ in maize plants treated with fulvic acid $(F A)$ and superabsorbent polymer (SAP) under well-watered (WW) and water deficit (WD) conditions for 12 (a) or $18 \mathrm{~d}$ (b), respectively.
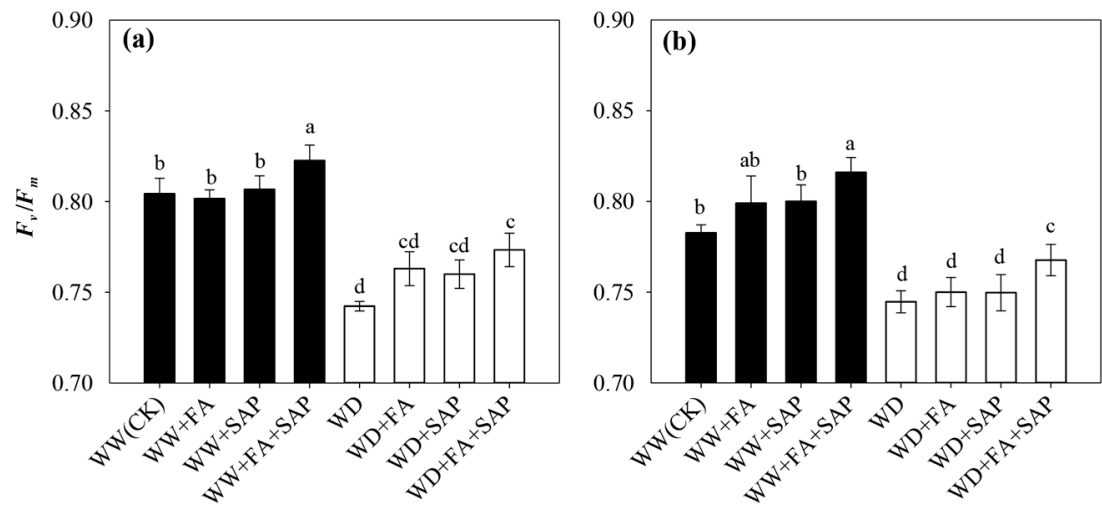

Different letters above columns indicate significant differences at $\alpha=0.05$. 
Table 2. Osmotic potential $\left(\Psi_{\pi}\right)$, relative water content (RWC), and leaf proline for maize plants treated with fulvic acid (FA) and super-absorbent polymer (SAP) under well-watered (WW) and waterdeficit (WD) conditions for 12 or $18 \mathrm{~d}$.

\begin{tabular}{|c|c|c|c|c|c|c|}
\hline \multirow[b]{2}{*}{ Treatment } & \multicolumn{2}{|c|}{$\Psi_{\pi}$} & \multicolumn{2}{|c|}{ RWC } & \multicolumn{2}{|c|}{ Proline } \\
\hline & $12 \mathrm{~d}$ & $18 \mathrm{~d}$ & $12 \mathrm{~d}$ & $18 \mathrm{~d}$ & $12 \mathrm{~d}$ & $18 \mathrm{~d}$ \\
\hline & \multicolumn{2}{|c|}{$-\mathrm{MPa}=$} & \multicolumn{2}{|c|}{$\%$} & \multicolumn{2}{|c|}{$-\mu \mathrm{mol} \mathrm{g}{ }^{-1} \mathrm{FW}-$} \\
\hline WW (CK) & $-1.12 \mathrm{a}$ & $-1.27 \mathrm{ab}$ & $91.77 \mathrm{a}$ & $80.57 b c$ & $19.16 \mathrm{e}$ & 27.61de \\
\hline WW+FA & $-1.16 \mathrm{a}$ & $-1.24 a b$ & $90.87 \mathrm{a}$ & $83.57 \mathrm{ab}$ & $24.97 \mathrm{de}$ & $31.64 d$ \\
\hline WW+SAP & $-1.12 \mathrm{a}$ & $-1.33 b c$ & $96.43 \mathrm{a}$ & $81.93 \mathrm{bc}$ & $24.02 \mathrm{de}$ & $23.15 \mathrm{e}$ \\
\hline $\mathrm{WW}+\mathrm{FA}+\mathrm{SAP}$ & $-1.08 \mathrm{a}$ & $-1.19 \mathrm{a}$ & $93.10 \mathrm{a}$ & $86.93 \mathrm{a}$ & $26.97 \mathrm{~d}$ & $30.12 d$ \\
\hline WD & $-1.46 b c$ & $-1.61 \mathrm{e}$ & $76.83 \mathrm{c}$ & $68.70 \mathrm{~d}$ & $36.55 \mathrm{c}$ & $57.44 \mathrm{c}$ \\
\hline WD+FA & $-1.40 \mathrm{~b}$ & $-1.51 \mathrm{de}$ & $77.33 \mathrm{bc}$ & $66.93 \mathrm{~d}$ & $48.59 \mathrm{a}$ & $77.97 \mathrm{a}$ \\
\hline $\mathrm{WD}+\mathrm{SAP}$ & $-1.55 c$ & $-1.49 \mathrm{~d}$ & $79.73 c$ & $69.90 \mathrm{~d}$ & $40.22 b c$ & $62.79 \mathrm{c}$ \\
\hline $\mathrm{WD}+\mathrm{FA}+\mathrm{SAP}$ & $-1.36 b$ & $-1.42 \mathrm{~cd}$ & $84.30 \mathrm{~b}$ & $76.23 \mathrm{c}$ & $43.12 \mathrm{ab}$ & $69.61 \mathrm{~b}$ \\
\hline ANOVA (main effects) & & & & & & \\
\hline Moisture & ** & $* *$ & $* *$ & ** & $* *$ & $* *$ \\
\hline FA & * & $*$ & ns & * & $* *$ & $* *$ \\
\hline SAP & ns & * & ${ }^{*}$ & ns & ns & $\mathrm{ns}$ \\
\hline Moisture×FA & * & ns & ns & ns & ns & ${ }^{*}$ \\
\hline Moisture $\times$ SAP & ns & * & ns & ns & ns & ns \\
\hline $\mathrm{FA} \times \mathrm{SAP}$ & ns & ns & ns & * & " & ns \\
\hline Moisture $\times \mathrm{FA} \times \mathrm{SAP}$ & ns & ns & $\mathrm{ns}$ & ns & ns & * \\
\hline
\end{tabular}

Values followed by different letters within each column are significantly different according to Duncan's test at $\alpha=0.05$.

", "* Significant at $\alpha=0.05$ and $\alpha=0.01$, respectively; ns: nonsignificant differences; FW: fresh weight.

12 or 18 , the RWC levels significantly improved by $15.1 \%$ and $12.8 \%$ after the combined treatment, respectively, compared with the untreated control plants; these increases were higher than when either treatment was used alone.

After 12 or $18 \mathrm{~d}$ of WD, and in the absence of the two chemicals, proline levels increased by $90.7 \%$ and $100.8 \%$, respectively, compared with the WW group (CK). When compared with CK at 12 or $18 \mathrm{~d}$ after being subjected to WD, leaf proline increased by 1.26 and 1.55 times with the FA application alone, 1.1 and 1.3 times when applying SAP alone, and 1.52 and 1.85 times, respectively, when applying both chemicals. After $12 \mathrm{~d}$ of WD and compared with the control plants, leaf proline levels increased by $39.2 \%$ in the FA only spraying and $23.9 \%$ in the combined FA and SAP treatment. For a prolonged duration and under WD conditions $(18 \mathrm{~d})$, the combined use of both chemicals significantly increased proline by $30.1 \%$ compared with the SAP treatment alone and 13\% compared with the FA treatment alone. In contrast, after 12 or $18 \mathrm{~d}$ under WW conditions, proline levels were not significantly different between FA and SAP treatments alone or combined. For the two samplings (12 d and $18 \mathrm{~d}$ water control), $\mathrm{F}_{\mathrm{v}} / \mathrm{F}_{\mathrm{m}}$ was significantly associated with RWC and $\Psi_{\pi}\left(\mathrm{R}^{2}=0.55\right.$ and $0.38, \mathrm{P}<0.05$, respectively $)$ under WD conditions with FA and SAP alone or combined, but there were nonsignificant correlations between $\Psi_{\pi}$ and proline or between RWC and $\Psi_{\pi}$.

\section{Yield components}

When the treatment did not include the two chemicals, yield was 37\% lower in the WD group than in the WW group (CK) (Figure 6). Compared with CK, yield under WD conditions treated with FA or SAP alone decreased by 26\% and $32 \%$, respectively. However, yield decreased by $20 \%$ under WD conditions when treated with combined FA and SAP and compared with CK. Fulvic acid spraying alone led to a 13\% shoot biomass increase under WW conditions but did not change biomass under WD conditions. Under WW conditions, FA and SAP used alone had no effect on yield and yield components under WW conditions; the combined application increased yield (12.3\%) and grain weight (16.5\%). In contrast, both chemicals combined increased yield (19.1\%) and number of grains (23.1\%) under WD conditions. Under WD conditions, yield in the combined treatment was $14 \%$ and $7 \%$ higher than with SAP and FA alone. 


\section{DISCUSSION}

Foliar FA or soil SAP alone significantly increased in $\mathrm{P}_{n(\max )}$ and $\mathrm{Q}_{\mathrm{y}}$ under two watering conditions. This observation is similar to previously reported findings (Anjum et al., 2011; Mao et al., 2011). The combined treatment under two soil water regimes significantly improved $\mathrm{Q}_{\mathrm{y}}$ and $\mathrm{P}_{\mathrm{n}(\max )}$ (Table 1). Plant capacity to absorb light increased $\mathrm{Q}_{\mathrm{y}}$ in plots treated with the chemicals. However, the compensating effects of combining FA and SAP on $\mathrm{P}_{\text {max }}$ and $\mathrm{Q}_{\mathrm{y}}$ under WD conditions were higher than under WW conditions. Therefore, the use of both FA and SAP is more valuable and effective under dry conditions. It was concluded that combining the two chemicals could mitigate the effects of soil water deficit in plants when compared with using either chemical alone. In a pot experiment with maize plants, Yang et al. (2017) found that the combined use of FA and SAP effectively maintained a high net photosynthetic rate and decreased leaf stomatal transpiration under drought conditions. The first of two possible mechanisms for these is that SAP improves water-holding capacity in water deficient soils, maintains better soil water status around the roots (Islam et al., 2011), and allows easier uptake of mineral nutrients and water by the roots and transportation to the shoot (Celik et al., 2010). Root water uptake was significantly improved when the two chemicals were applied to maize plants under low rainfall conditions (Liao et al., 2018b). Secondly, foliar FA spraying improves the diphosphate ribulose carboxylase and oxygenase levels of the photochemical reaction (Canellas et al., 2015); photosynthesis and yield are therefore enhanced (Calvo et al., 2014). Zhang et al. (2016) reported that foliar FA was more useful under relatively good soil moisture conditions and improved the photosynthetic rate and plant growth.

The $F_{v} / F_{m}$ ratio is a parameter to evaluate potential photochemical conversion efficiency of photosystem II. As $\mathrm{F}_{\mathrm{v}} / \mathrm{F}_{\mathrm{m}}$ levels lower, the degree of inhibition of photosynthetic efficiency becomes more obvious (Singh and Reddy, 2014). Fulvic acid spraying improved the $F_{v} / F_{m}$ ratio under both watering regimes (Figure 4). These results are similar to those obtained by Lotfi et al. (2018), who also reported that FA spraying improves $F_{v} / F_{m}$ and the performance index of rapeseed plants under WD and WW conditions. It also increased photosynthesis. The $\mathrm{Chl}(\mathrm{a}+\mathrm{b})$ content under both moisture conditions did not significantly change when FA was applied alone (Figure 3). Few studies show that foliar FA spraying has little effect on Chl (a+b) content (Goreta et al., 2007; Celik et al., 2010; Yang et al., 2019). However, Anjum et al. (2011) demonstrated that $\mathrm{Chl}(\mathrm{a}+\mathrm{b})$ in maize plants significantly improves by FA spraying under WD and WW conditions. Possible reasons for these differences are related to the time and rate of FA application (Calvo et al., 2014). The addition of SAP to soil significantly improved $\mathrm{Chl}(\mathrm{a}+\mathrm{b})$ under both moisture regimes. This finding is also similar to previous reports (Koupai et al., 2008; Celik et al., 2010). Under the two watering regimes, $\mathrm{F}_{\mathrm{v}} / \mathrm{F}_{\mathrm{m}}$ and $\mathrm{Chl}(\mathrm{a}+\mathrm{b})$ exhibited an increasing trend for the combined treatment when compared with individual applications of either chemical. The combined application of FA and SAP was more beneficial for protecting the chloroplast structure and electron transport chain from water deficit. Soil moisture improved even under drought stress conditions in plants sprayed with SAP, while foliar FA spraying improved plant $\mathrm{Chl}(\mathrm{a}+\mathrm{b})$ (Khadem et al., 2010). The mechanism for this phenomenon is potentially related to maize $\mathrm{N}$ uptake (Calvo et al., 2014). Nitrogen contents in maize plant roots increased in a dryland cropping system involving FA and SAP application (Liao et al., 2018b).

The improvement in proline levels contributes to osmotic adjustment in the cytoplasm and/or plant chloroplasts (Farooq et al., 2009). This active responsive mechanism improves plant tissue water, mitigates dehydration-induced physiological/biochemical damages, and enhances plant survival under drought conditions (Campos et al., 2004; Mahajan and Tuteja, 2005). However, this effect only occurs when leaf turgor is maintained within a critical range (del Amor et al., 2010). It has been reported that cells increase the amount of proline only when plant tissue hydration decreases from approximately 70\% to 75\% of RWC (Good and Zaplachinski, 1994). After $18 \mathrm{~d}$ of WD, FA caused a significant increase in proline levels and $\Psi_{\pi}$ when RWC was $<70 \%$ (Table 2, Figure 5). This result was not entirely in accordance with previous results obtained using pot experiments. Foliar FA spraying resulted in a large increase in RWC and proline in maize plants under drought conditions, while 60\% RWC was more favorable to proline accumulation (Anjum et al., 2011). In potato plants, RWC and leaf proline did not respond to FA under slight water deficit, but they significantly increased at a low irrigation level (Aggag et al., 2015). A pot test with pepper plants found that spraying a foliar antitranspirant did not affect proline and RWC after severe drought stress, whereas it increased in both parameters after a moderate water deficiency treatment (del Amor et al., 2010). It was suggested that leaf proline accumulation in plants treated with FA is possibly specific to the crop type and severity of water deficiency (Goreta et al., 2007). 
Applying SAP to the soil had no effect on proline under drought and well-watered conditions (Table 2). Maize plants can show a better adaptation to soil water deficit after SAP application when good soil moisture and leaf water potential are maintained (Najafinezhad et al., 2015; Cao et al., 2017).

Under prolonged WD conditions, RWC and proline were higher under the SAP+FA treatment than when used alone; this also indirectly improved the photosynthetic efficiency of photosystem II. A possible cause for this was the fact that two leaf water and proline measurements were performed when the plants were subjected to severe water shortage (Figure 1). In the later crop growth stage, plants growing under water deficit conditions are affected by severe cell dehydration and plant tissue wilting due to a rapid decrease in RWC and $\Psi_{\pi}$, which is not favorable for leaf proline accumulation when RWC is $<70 \%$ (Good and Zaplachinski, 1994). The SAP application to the soil increases leaf RWC and water potential under drought conditions and also increases crop water consumption (Islam et al., 2011). Fulvic acid spraying limits SAPinduced water loss in a soil-maize system by decreasing leaf stomatal conductance under drought conditions (Yang et al., 2017). This favorable regulation improved soil moisture and maintained suitable RWC to lessen plant dehydration (Figure 5); it has the potential to trigger leaf proline to improve plant survival.

Increased yield was largely attributed to an increase in the number of grains when FA and SAP were applied together in maize (Figure 6). This could be closely related to pollen viability as well. Weerasinghe et al. (2016) tested an antitranspirant spray in plants during the reproductive phase under WD conditions and observed increased pollen viability and grain setting. Increased yield under the WW condition with FA and SAP application was mainly due to an increase in grain weight. Crop growth and physiological performance were acceptable under WW conditions (Figures 2-5). Therefore, yield can be higher in plants under these conditions (Figure 5). By using the two chemicals and good water irrigation, crops can attain high chlorophyll content and photosynthetic efficiency (Figures 3 and 4). As a result, grain filling characteristics are more likely to be positively reflected in the yield. Zhang et al. (2016) found that FA spraying improved grain filling and increased grain weight of wheat grown under well-irrigated conditions. Therefore, two mechanisms contribute to improved yield under contrasting soil moisture conditions, that is, when treated with FA and SAP. Yield under WW conditions treated with these two chemicals was lower than when treated with them under WD conditions. When compared with CK treatment, a possible cause for increases in net photosynthetic rate and photosynthetic efficiency of photosynthetic system II under WD conditions when treated with FA and SAP is that they were higher than under WW conditions treated with FA and SAP (Table 1). Therefore, soil SAP combined with foliar FA spraying would be more important and beneficial to improve photosynthesis and production under WD conditions.

Figure 5. Linear regression relationships between the fluorescent parameter $\left(F_{v} / F_{m}\right)$, leaf relative water content $(R W C)$, and proline in maize plants treated with fulvic acid (FA) and superabsorbent polymer (SAP) under water deficit conditions.
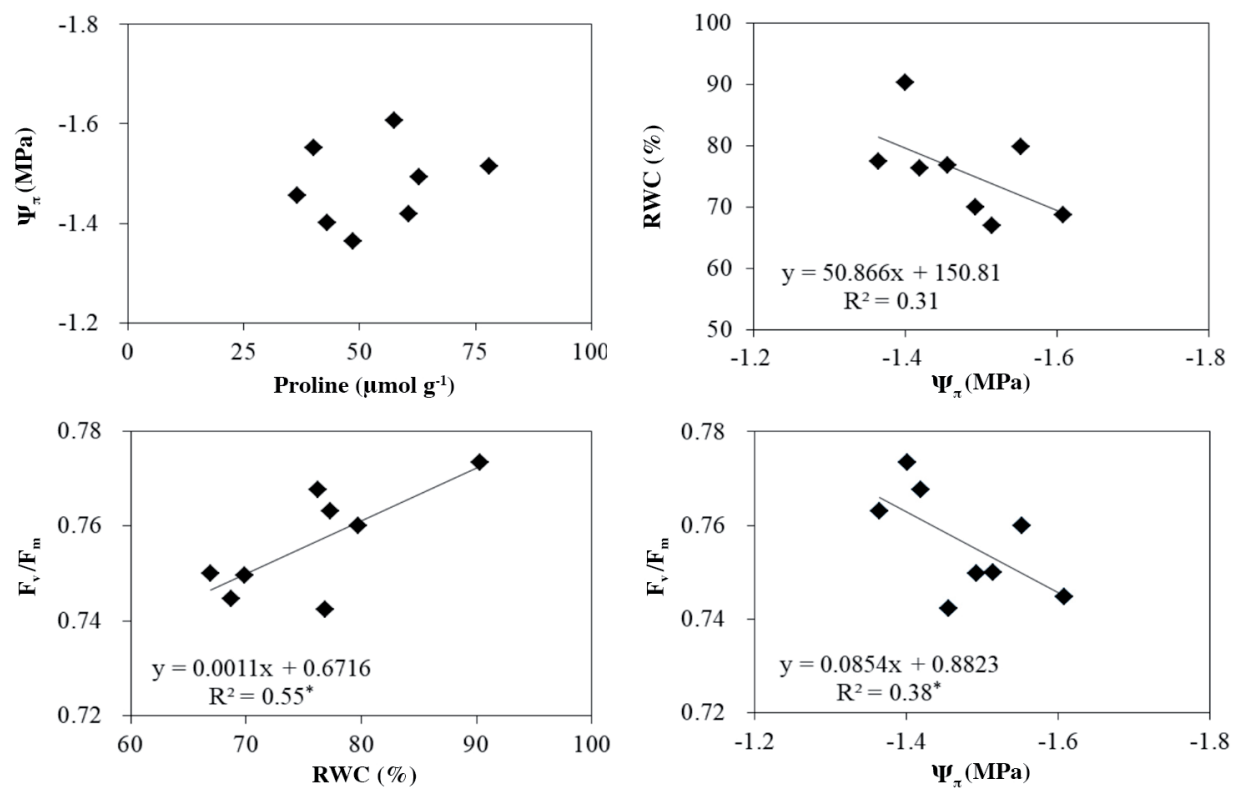

$\Psi_{\pi}$ : Osmotic potential. 
Figure 6. Yield and yield components for maize plants treated with fulvic acid (FA) and superabsorbent polymer (SAP) under well-watered (WW) and water deficit (WD) conditions.
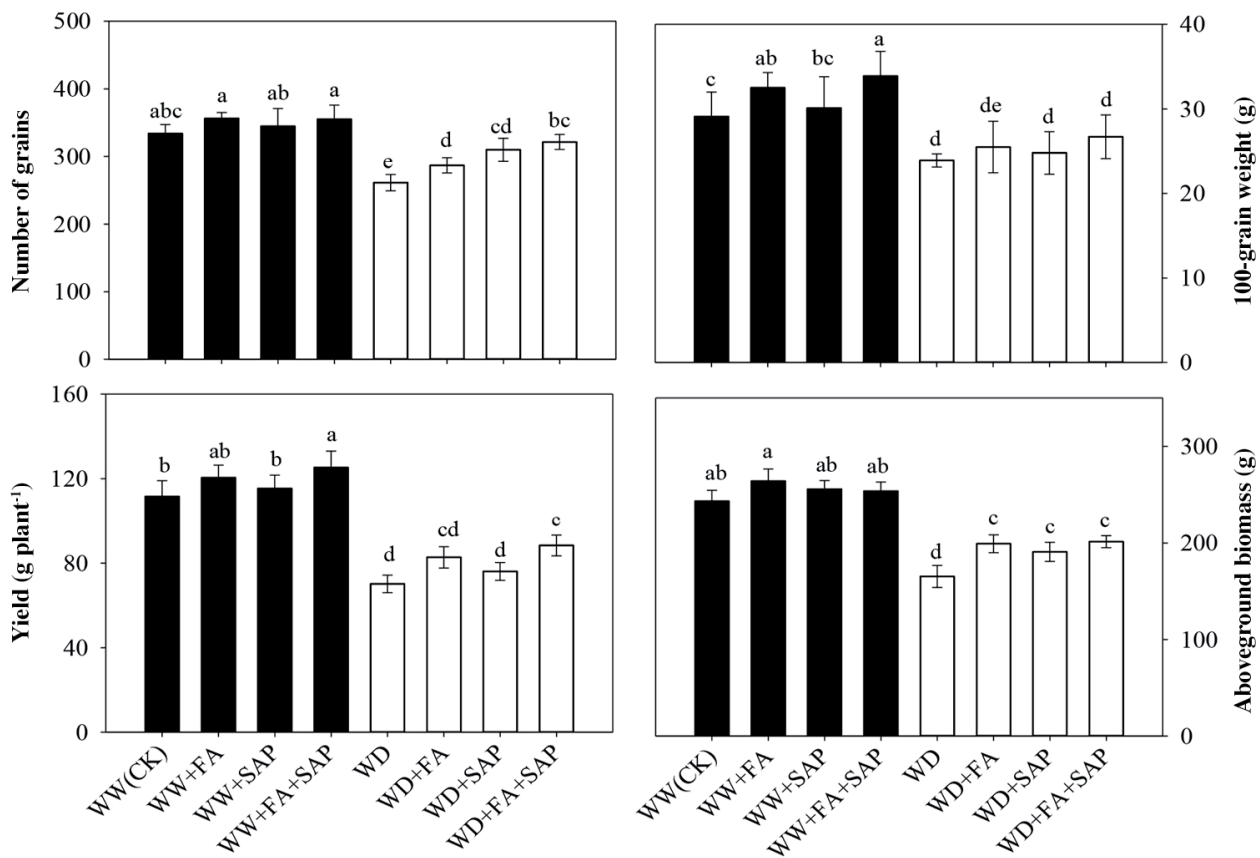

\section{CONCLUSIONS}

The application of both superabsorbent polymer (SAP) and fulvic acid (FA) significantly increased maize yield under water deficit (WD) and well-watered (WW) conditions; these increases were greater than increases achieved by applying them alone. Increased yield under WD conditions treated with FA and SAP was largely attributed to the increased number of grains. Regardless of the watering regime, the combined use of both chemicals improved the net photosynthetic rate and chlorophyll level, thereby enhancing potential photosynthetic efficiency of photosystem II. Leaf proline and water content improved under WD conditions when treated with these chemicals. It is suggested that the combined use of SAP and FA could be incorporated in maize production practices to maintain high leaf proline levels and improve photosynthetic efficiency to achieve higher yields even under water deficit conditions.

\section{ACKNOWLEDGEMENTS}

The research work was supported by the Science and Technology Innovation Project of Inner Mongolia of China (KCBJ2018050) and the China Scholarship Council (201706350218).

\section{REFERENCES}

Aggag, A.M., Alzoheiry, A.M., and Abdallah, A.E. 2015. Effect of kaolin and fulvic acid antitranspirants on tomato plants grown under different water regimes. Alexandria Science Exchange Journal 36:169-178.

Anjum, S.A., Wang, L., Farooq, M., Xue, L., and Ali, S. 2011. Fulvic acid application improves the maize performance under well-watered and drought conditions. Journal of Agronomy and Crop Science 197:409-417.

Ashraf, M., Akram, N.A., Al-Qurainy, F., and Foolad, M.R. 2011. Chapter five-drought tolerance: roles of organic osmolytes, growth regulators, and mineral nutrients. Advances in Agronomy 111:249-296.

Bates, L.S., Waldren, R.P., and Teare, I.D. 1973. Rapid determination of free proline for water-stress studies. Plant and Soil 39:205-207.

Calvo, P., Nelson, L., and Kloepper, J.W. 2014. Agricultural uses of plant biostimulants. Plant and Soil 383:33-41.

Campos, H., Cooper, M., Habben, J.E., Edmeades, G.O., and Schussler, J.R. 2004. Improving drought tolerance in maize: a view from industry. Field Crops Research 90:19-34. 
Canellas, L.P., Olivares, F.L., Aguiar, N.O., Jones, D.L., Nebbioso, A., Mazzei, P., et al. 2015. Humic and fulvic acids as biostimulants in horticulture. Scientia Horticulturae196:15-27.

Cao, Y.B., Wang, B.T., Guo, H.Y., Xiao, H.J., and Wei, T.T. 2017. The effect of super absorbent polymers on soil and water conservation on the terraces of the loess plateau. Ecological Engineering 102:270-279.

Cattivelli, L., Rizza, F., Badeck, F.W., Mazzucotelli, E., Mastrangelo, A.M., Francia, E., et al. 2008. Drought tolerance improvement in crop plants: an integrated view from breeding to genomics. Field Crops Research 105:1-14.

Celik, H., Katkat, A.V., Asik, B.B., and Turan, M.A. 2010. Effect of foliar-applied humic acid to dry weight and mineral nutrient uptake of maize under calcareous soil conditions. Communications in Soil Science and Plant Analysis 42:29-38.

del Amor, F.M., Cuadra-Crespo, P., Walker, D.J, Cámara, J.M., and Madrid, R. 2010. Effect of foliar application of antitranspirant on photosynthesis and water relations of pepper plants under different levels of $\mathrm{CO}_{2}$, and water stress. Journal of Plant Physiology 167:1232-1238.

Delfine, S., Tognetti, R., Desiderio, E., and Alvino, A. 2005. Effect of foliar application of N and humic acids on growth and yield of durum wheat. Agronomy for Sustainable Development 25:183-191.

Faralli, M., Grove, I.G., Hare, M.C., Alcalde-Barrios, A., William, K.S., Corke, F.M.K., et al. 2017. Modulation of Brassica napus source-sink physiology through film antitranspirant induced drought tolerance amelioration that is dependent on the stress magnitude. Journal of Agronomy and Crop Science 203:360-372.

Farooq, M., Wahid, A., Kobayashi, N., Fujita, D., and Basra, S.M.A. 2009. Plant drought stress: effects, mechanisms and management. Agronomy Sustainable Development 29:185-212.

Good, A.G., and Zaplachinski, S.T. 1994. The effects of drought stress on free amino acid accumulation and protein synthesis in Brassica napus. Physiologiae Plantarum 90:9-14.

Goreta, S., Leskovar, D.I., and Jifon, J.L. 2007. Gas exchange, water status, and growth of pepper seedlings exposed to transient water deficit stress are differentially altered by antitranspirants. Journal of the American Society for Horticultural Science 132:603-610.

Hartwigsen, J.A., and Evans, M.R. 2000. Humic acid seed and substrate treatments promote seedling root development. HortScience 35:1231-1233.

Islam, M.R., Hu, Y.G., Mao, S.S., Mao, J.Z., Enjji, C., Eneji, A.E., et al. 2011. Effectiveness of a water-saving super-absorbent polymer in soil water conservation for corn (Zea mays L.) based on eco-physiological parameters. Journal of the Science of Food and Agriculture 91:1998-2005.

Khadem, S.A., Galavi, M., Ramrodi, M., Mousavi, S.R., Rousta, M.J., and Rezvani-Moghadam, P. 2010. Effect of animal manure and superabsorbent polymer on corn leaf relative water content, cell membrane stability and leaf chlorophyll content under dry condition. Australian Journal of Crop Science 4:642-647.

Koupai, J.A., Eslamian, S.S., and Kazemi, J.A. 2008. Enhancing the available water content in unsaturated soil zone using hydrogel, to improve plant growth indices. Ecohydrology and Hydrobiology 8:67-75.

Li, X.Y. 2003. Gravel-sand mulch for soil and water conservation in the semiarid loess region of northwest China. Catena 52:105-127.

Li, M.S., Li, S., Zhang, S.Y., and Chi, B.L. 2005. Physiological effect of new FA antitranspirant on winter wheat at ear filling stage. Agricultural Science in China 4:820-825.

Liao, R., Yang, P., Yu, H., Wu, W., and Ren, S. 2018a. Establishing and validating a root water uptake model under the effects of superabsorbent polymers. Land Degradation and Development 29:1478-1488.

Liao, R., Zhang, L., Yang, P., Wu, W., and Zhang, Z. 2018b. Physiological regulation mechanism of multi-chemicals on water transport and use efficiency in soil-maize system. Journal of Cleaner Production 172:1289-1297.

Lobo, F.D.A., De Barros, M.P., Dalmagro, H.J., Dalmolin, A.C., Pereira, W.E., de Souza, E.C., et al. 2013. Fitting net photosynthetic light-response curves with Microsoft Excel-a critical look at the models. Photosynthetica 51:445-456.

Lotfi, R., Kalaji, H.M., Valizadeh, G.R., Behrozyar, E.K., Hemati, A., Gharavi-Kochebagh, P., et al. 2018. Effects of humic acid on photosynthetic efficiency of rapeseed plants growing under different watering conditions. Photosynthetica 56:962-970.

Lotfi, R., Pessarakli, M., Gharavi-Kouchebagh, P., and Khoshvaghti, H. 2015. Physiological responses of Brassica napus to fulvic acid under water stress: Chlorophyll a fluorescence and antioxidant enzyme activity. Crop Journal 3:434-439.

Mahajan, S., and Tuteja, N. 2005. Cold, salinity and drought stresses: An overview. Archives of Biochemistry and Biophysics 444:139-158.

Maibodi, N.D.H., Kafi, M., Nikbakht, A., and Rejali, F. 2015. Effect of foliar applications of humic acid on growth, visual quality, nutrients content and root parameters of perennial ryegrass (Lolium perenne L.) Journal of Plant Nutrition 38:224-236.

Mao, S.S., Islam, M.R., Xue, X.Z., Zeng, Z.H., and Hu, Y.G. 2011. Effects of water-retaining agent and water supply tension on physiology, growth and water use efficiency of corn. Transaction of Chinese Society of Agricultural Engineering 27:82-88. (In Chinese with English Abstract).

Moini, N., and Kabiri, K. 2015. Effective parameters in surface cross-linking of acrylic-based water absorbent polymer particles using bisphenol a diethylene glycidyl ether and cycloaliphatic diepoxide. Iran Polymer Journal 24:977-987. 
Najafinezhad, H., Sarvestani, Z.T., and Naghavi, H. 2015. Evaluation of yield and some physiological changes in corn and sorghum under irrigation regimes and application of barley residue, zeolite and superabsorbent polymer. Archives of Agronomy and Soil Science 61:891-906.

Singh, S.K., and Reddy, V.R. 2014. Combined effects of phosphorus nutrition and elevated carbon dioxide concentration on chlorophyll fluorescence, photosynthesis, and nutrient efficiency of cotton. Journal of Plant Nutrition and Soil Science 177:892-902.

Suh, H.Y., Yoo, K.S., and Sang, G.S. 2016. Erratum to: Effect of foliar application of fulvic acid on plant growth and fruit quality of tomato (Lycopersicon esculentum L.) Horticultural Environment and Biotechnology 55:455-461.

Weerasinghe, M.M., Kettlewell, P.S., Grove, I.G., and Hare, M.C. 2016. Evidence for improved pollen viability as the mechanism for film antitranspirant mitigation of drought damage to wheat yield. Crop Pasture Science 67:137-146.

Yang, W., Li, P.F., Guo, S.W., Fan, B.Q., Song, R.Q., and Yu, J. 2017. Compensating effect of fulvic acid and super-absorbent polymer on leaf gas exchange and water use efficiency of maize under moderate water deficit conditions. Plant Growth Regulation 83:451-460.

Yang, L.X., Yang, Y., Chen, Z., Guo, C.X., and Li, S.C. 2014. Influence of super absorbent polymer on soil water retention, seed germination and plant survivals for rocky slopes eco-engineering. Ecological Engineering 62:27-32.

Yang, W., Guo, S., Li, P., Song, R., and Yu, J. 2019. Foliar antitranspirant and soil superabsorbent hydrogel affect photosynthetic gas exchange and water use efficiency of maize grown under low rainfall conditions. Journal of the Science of Food and Agriculture 99:350-359.

Ye, Z.P., Suggett, D.J., Robakowski, P., and Kang, H.J. 2013. A mechanistic model for the photosynthesis-light response based on the photosynthetic electron transport of photosystem II in $C_{3}$ and $C_{4}$ species. New Phytologist 199:110-120.

Yu, J., Shi, J.G., Ma, X., Dang, P.F., Yan, Y.L., Mamedov, A.I., et al. 2017. Superabsorbent polymer properties and concentration effects on water retention under drying conditions. Soil Science Society of America Journal 81:889-901.

Zhang, X.Y., Zhang, X.Y., Liu, X.W., Shao, L.W., Sun, H.Y., and Chen, S.Y. 2016. Improving winter wheat performance by foliar spray of ABA and FA under water deficit conditions. Journal of Plant Growth Regulation 35:83-96. 